\title{
LA CUENTA DE INVERSIÓN \\ DE LA PROVINCIA DE SANTA FE \\ EN EL MARCO DEL PROCESO \\ DE ARMONIZACIÓN CON LAS NORMAS \\ INTERNACIONALES DE CONTABILIDAD \\ PARA EL SECTOR PÚBLICO (NICSP)
}

\author{
Tesista \\ Luciana María Tombolato \\ Directora de tesis \\ Carmen Inés Giachino de Palladino
}

La globalización, como consecuencia del cambio de paradigmas del mundo actual, plantea ciertas oportunidades y riesgos que varían en su intensidad según los diferentes territorios. Para alcanzar los beneficios que plantea la nueva realidad internacional, se hace necesario que los Estados y demás actores económicos y políticos afronten mayores desafíos y adopten nuevas reglas de juego.

Según Oslak (2003), "el cambio en el sector público no puede ser ajeno (en realidad, debe acompañar) a las grandes transformaciones que, simultáneamente, tienen lugar en la sociedad, la economía y el contexto internacional». Por ser la contabilidad un lenguaje, y en un mundo cada vez más globalizado, se hace necesario que ese lenguaje sea universal. En ese sentido, es importante la labor que lleva a cabo la Federación Internacional de Contadores Públicos (IFAC) en la emisión de normas contables a nivel internacional y la Federación Argentina de Consejos Profesionales de Ciencias Económicas en la emisión de Recomendaciones Técnicas para el Sector Público (RTSP) a nivel nacional.

La iniciativa de esta investigación surgió porque uno de los aspectos a considerar cuando se analizan los sistemas contables públicos, es el proceso de armonización que está teniendo lugar a nivel internacional, resultando tema de discusión en diversos Congresos, Jornadas, Simposios y otros eventos que involucran al sector público. En los mismos se viene abordando la importancia de aplicar las NICSP, analizando las mismas en su contenido y en los beneficios que reporta su utilización. Asimismo, del relevamiento de información realizado, surge que existen trabajos que cotejan las NICSP con la información contenida en las Cuentas de Inversión de diversos países, entre los que podemos mencionar los casos de Argentina, Chile y México.

¿Cuáles son los beneficios de la armonización? Armonizar con las NICSP permitiría a los diferentes niveles de gobierno contar con información más confiable, comparable, 
de calidad y transparente, a la vez que posibilitaría una mejor rendición de cuentas. La convergencia normativa supone avanzar en la modernización de los sistemas contables y reducir sus diferencias.

Como contrapartida, y citando a Fermín del Valle, como obstáculos o desafíos de la convergencia internacional podemos enunciar la traducción de las normas a los distintos idiomas y la complejidad y estructura de las normas contables internacionales. No obstante, remarca que las principales barreras no son esas, sino que tienen mayor incidencia en dicho proceso las cuestiones culturales, los modelos mentales y los aspectos políticos.

El cambio de paradigmas que se produjo a nivel mundial, la globalización y los procesos de Reforma de la Administración Financiera enmarcados en las Reformas de 2da. Generación, Ilevaron a que la Contabilidad Gubernamental adquiera un nuevo rol.

Este nuevo rol se refleja fundamentalmente en dos aspectos, uno tiene que ver con el criterio utilizado para determinar el resultado económico-financiero de la gestión, donde se pasa de un conceptualismo jurídico, a valorar el principio de la realidad económica, y en consecuencia, determinar el resultado a partir de la etapa del devengado. La utilización de este criterio no desnaturaliza la etapa del compromiso, que es presupuestaria y no contable, por lo cual queda como etapa de registro anterior con todas sus consecuencias jurídicas, y el control de responsabilidad propio de la hacienda pública. Con la aplicación del principio de la realidad económica, se busca mostrar a través de la etapa del devengado la verdadera incidencia económico-financiera de las transacciones que realiza el estado y su incidencia sobre el patrimonio gubernamental, registrando en el momento en que se produce la modificación cuantitativa y/o cualitativa del patrimonio.
Por otra parte, se observa que en las Leyes de Administración es vital el rol que asume la Contabilidad como núcleo integrador del resto de los subsistemas que componen la Administración Financiera Gubernamental. Se pasa a contar con un modelo contable, donde a partir de un registro único de las transacciones se obtienen todas las salidas de información necesarias. Esto evita duplicidad en los registros y diferencias en la información, a la vez que permite contar con un mayor número de informes sobre las cuentas públicas, avanzando en transparencia y rendición de cuentas.

\section{METODOLOGİA DE TRABAJO UTILIZADA}

El propósito de la investigación es conocer particularmente la situación actual de la Provincia de Santa Fe en el marco del proceso de armonización, en lo atinente a la información contenida en la Cuenta de Inversión correspondiente al ejercicio 2009 y los avances que se han ido realizando desde el año 2003 en cuanto a mejoramiento de la calidad de información y al acercamiento en relación a lo prescripto por las NICSP y las RTSP.

Para ello se definió como objetivo general el siguiente: investigar la evolución y situación actual del proceso de armonización de las Normas Internacionales de Contabilidad para el Sector Público en Argentina y particularmente sobre la situación de la Provincia de Santa Fe, siendo los objetivos específicos los que se mencionan a continuación:

- Cotejar la información contenida en los Estados Financieros integrantes de la Cuenta de Inversión de la Provincia de Santa Fe de los ejercicios 2003 y 2009 con lo requerido por las NICSP y por las RTSP y determinar el grado de coincidencia.

- Observar los avances que se han hecho en materia de transparencia y calidad de la información en la Provincia de Santa Fe en el período 2003-2009. 
- Analizar la Cuenta de Inversión de Santa Fe y abordar cuáles serían los principales cambios a realizar para adaptarse al suministro de información pública recomendado por la IFAC, determinando bajo qué marco legal se encuadrarían los mismos.

- Determinar si resultan aplicables legalmente las NICSP y las Recomendaciones Técnicas emitidas por la FACPCE al ámbito de la Provincia de Santa Fe.

- Abordar cuáles serían las consecuencias para la Provincia de Santa Fe de quedar al margen del proceso de armonización de las NICSP.

En base a lo expuesto anteriormente, se ha planteado la siguiente hipótesis descriptiva: La información contenida en los EEFF que forman parte de la Cuenta de Inversión de la Provincia de Santa Fe difiere de lo requerido por las NICSP y por las Recomendaciones Técnicas emitidas por la FACPCE.

Para testear la hipótesis, se determina el grado de coincidencia con las NICSP y con las Recomendaciones Técnicas de FACPCE en base a un índice mixto que incluye ambas normativas con dos niveles de análisis. En el primer nivel se tienen en cuenta los Estados Financieros (EEFF) que se deberían presentar en la Cuenta de Inversión según las normativas antes mencionadas, y en el segundo, se analizarán los elementos contenidos en cada uno de ellos. Se tomarán como referencia las NICSP No 1 "Presentación de Estados Financieros", NICSP № 2 "Estados de Flujo de Efectivo" y NICSP № 24 "Presentación de Información del Presupuesto en los Estados Financieros" y las RTSP № 1 "Marco Conceptual Contable para la Administración Públican y RTSP N ${ }^{\circ} 2$ «Presentación del Estado Contable de Ejecución Presupuestaria».

En cuanto a la metodología de cálculo, para ambos niveles de análisis, se procedió a puntuar cada uno de los elementos de acuerdo a si la información es coincidente, semejante o no coincidente. A su vez, para el primer nivel se ponderan los EEFF teniendo en cuenta si están previstos en ambos ordenamientos normativos o bien en uno sólo de los mismos; y para el segundo nivel se tiene en cuenta el porcentaje máximo ponderado asignado a cada EEFF en el primer nivel y luego se distribuye entre las distintas variables o elementos seleccionados para el mismo.

Se utiliza este tipo de instrumento, debido a que posibilita hacer un análisis de la situación, realizar un seguimiento de la misma y efectuar las correspondientes evaluaciones y posibles correcciones de desvíos. La información necesaria para elaborar el índice se encuentra disponible, es de fácil acceso y proviene de una fuente oficial. En el sitio web de la Provincia de Santa Fe se encuentra publicadas las Cuentas de Inversión correspondientes a los ejercicios 2003 a 2013.

Se analiza la Cuenta de Inversión porque es el instrumento previsto tanto en la Constitución de la Provincia de Santa Fe, como en la Ley de Administración Financiera que contiene los EEFF; y constituye la fuente de información que permite conocer la situación económica, financiera, patrimonial y de gestión del sector público.

\section{LOGROS 0 RESULTADOS PRINCIPALES}

Para el ejercicio 2003 se obtuvo una coincidencia del 42,86 \% para el primer nivel de análisis y un 31,75\% para el segundo nivel, lo que arroja una coincidencia global del $37,31 \%$. Los EEFF fueron presentados en cumplimiento a lo requerido por la Ley de Contabilidad, Decreto-Ley $1757 / 56$ y sus modificatorias. Como aspecto a destacar, podemos decir que en este ejercicio, se empieza a hacer un aprovechamiento parcial del SIPAF, mediante la utilización del módulo de gastos.

Ya en el ejercicio 2004, se acoplan los 
módulos de ejecución de recursos, cuentas bancarias y pagos, contabilidad, y responsables; comenzando así una verdadera etapa de integración de la ejecución presupuestaria con la contabilidad patrimonial, apoyada en procesos automáticos de registración que vinculan la clasificación por objeto del gasto y la clasificación por rubro de recursos con los planes de cuenta de la contabilidad. Complementariamente la Contaduría General de la Provincia estableció un Plan de Cuentas de Referencia y un Glosario de Cuentas Contables. En este ejercicio, se incorpora asimismo, el Estado de Resultados de la Administración Central, acompañado por el cuadro de compatibilización con el resultado económico que surge del Ahorro-Inversión-Financiamiento. Asimismo, el Estado General pasa a denominarse Estado de Situación Patrimonial, y se incorpora el rubro Patrimonio.

En el año 2005 se sanciona la Ley 12510 Ley de Administración, Eficiencia y Control del Estado. Esta ley tuvo origen en un proyecto unificado de ambas cámaras, luego de perder 4 veces consecutivas estado parlamentario.

En el año 2006 y con el nuevo encuadre jurídico de la Ley, se incorporan el Estado de Origen y Aplicación de Fondos y el Estado de Evolución del Patrimonio Neto. Incluyéndose en el Estado de Situación Patrimonial las amortizaciones de los bienes físicos. Se agrega como información complementaria el Anexo de Bienes de Uso. Por otra parte, se cambia la estructura del Estado de Situación del Tesoro, considerando los activos y pasivos a corto plazo clasificados en exigible y no exigible, dictándose a tal efecto la Disposición N ${ }^{\circ}$ 1 de CGP del año 2007. En dicha disposición se establece además la forma y plazo de presentación de estados contables.

Para el ejercicio 2009 se obtuvo una coincidencia del 85,71\% para el primer nivel de análisis y un 59,90 \% para el segundo nivel, lo que arroja una coincidencia global del $72,81 \%$. Como aspecto a destacar, en este ejercicio se incorpora una conciliación del resultado financiero del Ahorro-Inversión-Financiamiento y del Resultado Contable, y una compatibilización de los registros presupuestarios y contables.

Con respecto a la hipótesis planteada, podemos afirmar que la información contenida en los EEFF que forman parte de la Cuenta de Inversión de la Provincia de Santa Fe difiere de lo requerido por las NICSP y por las RTSP. Sin embargo, se observa un avance significativo, el cual se sustenta en los resultados antes expuestos. La convergencia normativa supondría entonces, seguir avanzando en la modernización de los sistemas contables actualmente vigentes.

\section{CONCLUSIONES}

La información contenida en la Cuenta de Inversión de la Provincia de Santa Fe presenta un nivel de coincidencia relativamente significativo, sin embargo, para adaptarse al suministro de información pública recomendado por la IFAC Ios principales cambios a realizar son:

- Utilizar la terminología propia de la normativa internacional, ya que uno de los objetivos de las NICSP es la unificación de términos. Un ejemplo de ello es la denominación de los EEFF y de algunos rubros como Propiedades, Planta y Equipos.

- Presentar en un nivel más agregado las distintas partidas de activos y pasivos del Estado de Situación Financiera y detallar la información por nota a los EEFF.

- Registrar los Inventarios y definir la forma de presentación en los EEFF.

- Incorporar en la contabilidad las Propiedades, Planta y Equipos y los Activos Intangibles adquiridos con anterioridad al 2004.

- Vincular el inventario de Bienes Registrables con la contabilidad. 
- Avanzar en la reglamentación del registro de la etapa del devengado de recursos, estableciendo políticas contables en la materia.

- Elaborar el Estado de Flujos de Efectivo sobre la base de la utilización del método directo, y regular los procedimientos necesarios para ello.

- Realizar un rediseño general de las Notas a los EEFF, teniendo en cuenta que tienen que estar debidamente referenciadas, y definir naturaleza y alcance de las mismas, a efectos de lograr su objetivo de brindar información complementaria $y / 0$ aclaratoria que facilite la comprensión de los mismos.

En lo expuesto hasta aquí, podemos decir que el diagnóstico realizado nos brinda una visión parcial del nivel de convergencia con las normas de contabilidad internacionales y nacionales, atento a que se consideró sólo parte del marco regulatorio vigente. Sin embargo en sí, constituye una primera etapa de reconocimiento de simetrías y asimetrías.

Para lograr la mencionada convergencia, se requiere entonces de un diagnóstico completo de situación, que incluya una evaluación de los requisitos a cumplir en base a la totalidad del marco regulatorio vigente, lo que nos permitirá conformar un cuadro de situación actual, detectando aspectos claves a tener en cuenta a la hora de diseñar un plan estratégi- co de convergencia. Este plan debe tener un enfoque integral, contemplar metas concretas y estar diseñado sobre la base a un cronograma de tareas a cumplir, con definición de tiempos y objetivos claros y precisos.

Por otra parte, es importante destacar el papel que los distintos Organismos Internacionales han tenido en la elaboración de las NICSP y en los procesos de modernización del Estado en general. Cada vez más, estos organismos recomiendan a los Estados miembros, la aplicación de normas y procedimientos que garanticen la transparencia de la información pública. Si en el futuro, las normas de los diferentes gobiernos no se adecuaran a lo prescripto a nivel internacional, se podría ver condicionado el acceso a las distintas líneas de préstamos, con el consiguiente incremento del riesgo país en sus distintos niveles gubernamentales.

Por último, si bien la aplicación de las NICSP permite incrementar la calidad y comparabilidad de la información financiera, a la vez que contribuye a mejorar la toma de decisiones y otorgar mayor transparencia a las cuentas públicas, por sí solas no son garantía de buenos resultados; se requiere apoyo político para llevar a cabo el proceso de armonización en todas sus etapas, y compromiso de todos los niveles de la organización, tanto en la definición de los pasos a seguir, como de la puesta en práctica.

\section{PARA CITAR ESTE ARTÍCULO:}

Tombolato, Luciana María (2014). «Recensión de tesis: “La Cuenta de Inversión de la provincia de Santa Fe en el marco del proceso de Armonización con las Normas Internacionales de Contabilidad para el Sector Público (NICSP)"”, DAAPGE, año 14, № 23, 2014, pp. 181-185. Santa Fe, Argentina: UNL. 
